\title{
HUBUNGAN KARAKTERISTIK TEMPAT PENAMPUNGAN AIR DAN PERILAKU MASYARAKAT DENGAN KEBERADAAN JENTIK Aedes aegypti DI KELURAHAN KARANGKLESEM, KECAMATAN PURWOKERTO SELATAN TAHUN 2016
}

\author{
Titha Yuda Pratiwi ${ }^{1)}$, M. Choiroel Anwar ${ }^{2)}$, Budi Utomo ${ }^{3)}$ \\ Jurusan Kesehatan Lingkungan, Politeknik Kesehatan Kemenkes Semarang, \\ Jl.Raya Baturaden KM 12 Purwokerto, Indonesia
}

\begin{abstract}
Abstrak
Penyakit Demam Berdarah Dengue (DBD) atau Dengue Hemorrhagic Fever (DHF) sampai saat ini merupakan salah satu masalah kesehatan masyarakat di Indonesia yang cenderung meningkat jumlah pasien serta semakin luas penyebarannya. Berdasarkan data rekapitulasi Pemantauan Jentik Berkala (PJB) Puskesmas Purwokerto Selatan di Kelurahan Karangklesem, terdapat 108 kontainer positif jentik dengan House Index $(\mathrm{HI})=4,3 \%$, Container Index $(C I)=5,6 \%$, Breteau Index $(B I)=31,6 \%$, dan Angka Bebas Jentik $(A B J)=95,7 \%$ namun menjadi salah satu daerah endemis dengan jumlah penderita DBD selama Januari sampai Desember 2015 sebesar 20 penderita dengan IR 1,54\%. Metode yang digunakan dalam penelitian ini bersifat observasional dengan rancangan penelitian cross-sectional. Hasil penelitian menunjukkan terdapat hubungan antara karakteristik penampungan air (TPA) dengan keberadaan jentik Aedes aegypti yaitu warna TPA, juga terdapat hubungan antara perilaku masyarakat dengan keberadaan jentik Aedes aegypti yaitu kebiasaan membersihkan TPA. membuktikan mengenai perilaku masyarakat yang erat hubungannya dengan keberadaan jentik Aedes aegypti yang ada di lingkungan Kelurahan Karangklesem. Untuk itu masyarakat diharapkan untuk kembali membenahi keadaan lingkungan sekitar Kelurahan Karangklesem dimulai dengan merubah perilaku masyarakat untuk lebih peduli dengan kebersihan lingkungan serta meminimalisir tempat perindukan nyamuk Aedes aegypti.
\end{abstract}

Kata kunci: Aedes aegypti, karakteristik TPA, perilaku masyarakat

\begin{abstract}
[The Correlation Of Characteristic Water Storage And Behavior Society To The Existence Of Larva Aedes aegypti In Karangklesem Village, South Purwokerto District Banyumas Regency In Year 2016] The disease of Demam Berdarah Dengue (DBD) or Dengue Hemorrhagic Fever is one of the public health problem in Indonesia which is likely to increase the number of patients and the increasingly widespread. Based on the recapitulation data of larva monitoring periodically (PJB) in local government clinic of karangklesem village south Purwokerto, there were 108 positive larva containers with House Index $(H I)=4.3 \%$, Container Index $(C I)=5.6 \%$, Breteau Index $(B I)=31.6 \%$, and $A B J=95.7 \%$, however those are became one of the endemic area with the number of dengue fever patients DBD during january to december 2015 amounted to 20 patients with IR 1.54\%. The method usage in this research is observational by cross-sectional research design. The result of research showed the correlation characteristics of water storage (TPA) between the existence of larva Aedes Aegypti are the color of water storage also there is a correlation between behavior society with the existence of larva Aedes Aegypti such as the habit of cleaning TPA. it prove about the behavior society who are closely related to the existence of larva Aedes Aegypti in Karangklesem village. Based on these conclusions are expected to the society to re-fix the environment around Karangklesem village it begins by changing behavior society to be more concerned with the cleanliness of environment and minimize the breeding places of Aedes aegypti.
\end{abstract}

Keywords: Aedes Aegypti, behavior societ, characteristics of TPA.

\footnotetext{
${ }^{1)}$ E-mail: Titha.yuda@gmail.com

${ }^{2)}$ E-mail: Choirul1960@gmail.com

${ }^{3)}$ E-mail: Abinuraga@gmail.com
} 


\section{Pendahuluan}

Penyakit Demam Berdarah Dengue (DBD) atau Dengue Hemorrhagic Fever (DHF) sampai saat ini merupakan salah satu masalah kesehatan masyarakat di Indonesia yang cenderung meningkat jumlah pasien serta semakin luas penyebarannya. Penyakit DBD di provinsi Jawa Tengah masih menjadi masalah prioritas. Hal ini terbukti bahwa 35 kabupaten/kota di Jawa Tengah sudah pernah terjangkit penyakit DBD. Dari tahun 2010 sampai 2014 angka kesakitan (IR) dan angka kematian (CFR) DBD di provinsi Jawa Tengah pada tahun 2010 sebesar (IR : 59,8/100.000 penduduk dan CFR ; 1,29\%) tahun 2011 sebesar (IR : 15,27/100.000 penduduk dan CFR ; 0,93\%) tahun 2012 sebesar (IR : 19,29/100.000 penduduk dan CFR ; 1,52\%) tahun 2013 sebesar (IR : 45,52/100.000 penduduk dan CFR ; 1.21\%) dan tahun 2014 sebesar (IR : 36,2/100.000 penduduk dan CFR ; 1,7\%). Angka kesakitan tertinggi di kota Semarang 97,31/100.000 penduduk dan terendah di kota Salatiga sebesar 4,97/100.000 penduduk. (Dinkes Provinsi Jawa Tengah, 2014).

Berdasarkan data rekapitulasi Pemantauan Jentik Berkala (PJB) Puskesmas Purwokerto Selatan, bahwa pada bulan September 2015 dilaksanakan survey PJB di Kelurahan Karangklesem dengan memeriksa 2.513 rumah dan 14.095 kontainer/penampungan air. Hasil pemeriksaan menunjukkan, ternyata ditemukan 108 rumah dan 795 kontainer positif jentik Aedes aegypti, sehingga didapatkan House Index (HI) $=4,3 \%$, Container Index (CI) = 5,6 \%, Breteau Index (BI) = 31,6 $\%$, dan Angka Bebas Jentik (ABJ) = 95,7 \% .

Penulis tertarik untuk meneliti hubungan tempat penampungan air dan perilaku dengan keberadaan jentik Aedes aegypti di Kelurahan Karangklesem, Kecamatan Purwokerto Selatan, dengan mempertimbangkan bahwa lingkungan rumah di Kelurahan Karangklesem, Kecamatan Purwokerto Selatan memungkinkan menjadi tempat perkembangbiakan nyamuk Aedes aegypti karena merupakan salah satu daerah endemis DBD dengan jumlah penderita DBD selama Januari sampai Desember 2015 sebesar 20 penderita dengan IR 1,54\%.

\section{Metode dan Riset}

Jenis penelitian yang akan dilakukan adalah penelitian observasional dengan menggunakan kuesioner sebagai alat pengumpul data pokok. Rancangan penelitian yang digunakan adalah cross sectional.

Populasi pada penelitian ini adalah rumah di

Kelurahan Karangklesem, Kecamatan Purwokerto Selatan yaitu sebanyak 2.513 rumah.

Adapun besar sampel dengan menggunakan rumus Minimum Sample Size, yaitu sebagai berikut :

$$
\mathrm{N}=\left[\frac{Z^{2}{ }_{1-\alpha / 2} \cdot P(1-P) N}{d^{2}(N-1)+Z^{2}{ }_{1-\alpha / 2} \cdot P(1-P)}\right]
$$

$$
\begin{aligned}
& =\frac{(1,96)^{2} \cdot 0,5(1-0,5) \cdot 2513}{(0,1)^{2}(2513-1)+(1,96)^{2} \cdot 0,5(1-0,5)} \\
\mathrm{n} & =\frac{2387,35}{26,07}=91,57 \approx 92 \text { sampel }
\end{aligned}
$$

Jadi jumlah sampel yang diambil sebesar 92 rumah

Keterangan :

n : besar sampel minimal

$\mathrm{N} \quad$ : jumlah populasi adalah 2.513 rumah

$\mathrm{Z}_{1-\alpha / 2}$ : standar deviasi normal untuk 1,96 dengan CI 95\%

d : presisi $(10 \%$ atau 0,1$)$

p : proporsi target populasi adalah $50 \%$ atau 0,5

1-p : proporsi tanpa atribut adalah 0,5 (Ariawan, 1998).

Cara pengambilan sampel pada penelitian ini menggunakan metode secara Cluster Random Sampling pada menggunakan cluster terkecil yaitu RT di Kelurahan Karangklesem sebanyak 62 RT. Analisis meliputi univariat, bivariat, dan multivariat.

\section{Hasil dan Pembahasan Hasil}

Kelurahan Karangklesem secara administrasi berada di wilayah Kecamatan Purwokerto Selatan, Kabupaten Banyumas yang terdiri dari 13 RW dan 62 RT. Berdasarkan data dari Kelurahan Karangklesem Kecamatan Purwokerto Selatan Kabupaten Banyumas luas wilayah Kelurahan Karangklesem 302 Ha. Batas wilayah Kelurahan Karangklesem adalah sebelah utara Kelurahan Purwokerto Kulon, sebelah selatan Desa Kedungrandu, sebelah timur Kelurahan Teluk, sebelah barat Kelurahan Karangpucung.

Penduduk Kelurahan Karangklesem Kecamatan Purwokerto Selatan Kabupaten Banyumas berjumlah 14.373 jiwa yang terdiri dari laki-laki 7.284 jiwa dan perempuan 7.089 jiwa dengan jumlah Kepala Keluarga (KK) adalah $4.397 \mathrm{KK}$.

Tabel 4.1. Distribusi Penduduk Menurut Mata Pencaharian di Kelurahan Karangklesem, Kecamatan Purwokerto Selatan Kabupaten Banyumas Tahun 2015

\begin{tabular}{llrr}
\hline No & Jenis Pekerjaan & $\begin{array}{c}\text { Jumlah } \\
\text { (jiwa) }\end{array}$ & $\begin{array}{c}\text { Persentase } \\
\text { (\%) }\end{array}$ \\
\hline 1 & Swasta & 4.844 & 33,7 \\
2 & Buruh & 3.910 & 27,7 \\
3 & Lain-lain & 3.593 & 25,0 \\
4 & Pensiunan & 934 & 6,5 \\
5 & PNS & 776 & 5,4 \\
6 & Karyawan & 316 & 2,2 \\
\hline & Jumlah & 14.373 & $100,0 \%$ \\
\hline
\end{tabular}


Sumber: Data Kelurahan Karangklesem Tahun 2015

Tabel 4.2. Distribusi Penduduk Menurut Tingkat Pendidikan di Kelurahan Karangklesem, Kecamatan Purwokerto Selatan Kabupaten Banyumas Tahun 2015

\begin{tabular}{llrr}
\hline No & Tingkat Pendidikan & Jumlah & $\begin{array}{c}\text { Prosentase } \\
(\mathbf{\% )}\end{array}$ \\
\hline 1 & S2 & 158 & 1,1 \\
2 & S1 & 1.567 & 10,9 \\
3 & D3 & 316 & 2,2 \\
4 & SMA & 3.435 & 23,9 \\
5 & SMP & 3.119 & 21,7 \\
6 & SD & 5.778 & 40,2 \\
\hline & Jumlah & 14.373 & 100,0 \\
\hline
\end{tabular}

Sumber: Data Kelurahan Karangklesem Tahun 2015

Perhitungan House Index (HI), Container Index (CI), Breteau Index (BI)dan Angka Bebas Jentik (ABJ) di Kelurahan Karangklesem

\begin{tabular}{llr}
\hline No & Variabel & Persentase (\%) \\
\hline 1. & ABJ & 56,5 \\
2. & HI & 43,5 \\
3. & CI & 24,0 \\
4. & BI & 102,0 \\
\hline
\end{tabular}

Hasil Analisis Univariat

Tabel 4.7. Hubungan Karakteristik Tempat Penampungan Air dan Perilaku Masyarakat dengan Keberadaan Jentik Aedes aegypti di Kelurahan Karangklesem, Kecamatan Purwokerto Selatan Kabupaten Banyumas Tahun 2016

\begin{tabular}{|c|c|c|c|c|}
\hline No & Variabel & Kategori & $\begin{array}{l}\text { Ju } \\
\text { ml } \\
\text { ah } \\
\text { (n) }\end{array}$ & $\%$ \\
\hline \multirow[b]{2}{*}{1.} & Keberadaan & Positif (ada) & 40 & 43,5 \\
\hline & $\begin{array}{l}\text { jentik Aedes } \\
\text { aegypti }\end{array}$ & $\begin{array}{l}\text { Negatif (tidak } \\
\text { ada) }\end{array}$ & 52 & 56,5 \\
\hline \multirow[t]{4}{*}{2.} & Jenis tempat & Semen & 14 & 15,2 \\
\hline & penampungan & Plastik & 40 & 43,5 \\
\hline & air & Seng/kaleng & 0 & 0 \\
\hline & & $\begin{array}{l}\text { Campuran } \\
\text { (Semen dan } \\
\text { plastik) }\end{array}$ & 38 & 47,8 \\
\hline \multirow[t]{3}{*}{3.} & Penempatan & Di luar rumah & 3 & 3,3 \\
\hline & tempat & Di dalam rumah & 45 & 48,9 \\
\hline & $\begin{array}{l}\text { penampungan } \\
\text { air }\end{array}$ & $\begin{array}{l}\text { Di luar dan di } \\
\text { dalam rumah }\end{array}$ & 44 & 47,8 \\
\hline \multirow[t]{2}{*}{4.} & Sumber air & PDAM & 23 & 25,0 \\
\hline & & $\begin{array}{l}\text { Sumber lainnya } \\
\text { (SGL, mata air, }\end{array}$ & 62 & 67,4 \\
\hline
\end{tabular}

air permukaan)

Campuran

(PDAM dan

SGL)

5. Warna tempat Gelap (hitam, 31 33,7 penampungan biru tua, abu, air

dil)

Terang (putih, $36 \quad 39,1$ merah, transparan, biru muda, dll)

Campuran (gelap dan terang)

6. Pemakaian

Tidak pernah

Pernah

7. Pemeliharaan

Tidak ada

ikan pemakan Ada

jentik

8. Kebiasaan

Kurang dari satu

membersihkan

tempat

penampungan

kali dalam seminggu

air

Satu kali atau

lebih dalam

seminggu

9. Kebiasaan Diletakkan

begitu saja

membuang

barang bekas

Diangkut

petugas

Dibakar

Ditimbun

10. Kebiasaan

Tidak selalu

Selalu

menutup

tempat

penampungan

air

\section{Tabel 4.17. Ringkasan Hasil Analisis Bivariat} Hubungan Karakteristik Tempat Penampungan Air dan Perilaku Masyarakat dengan Keberadaan Jentik Aedes aegypti di Kelurahan Karangklesem Kabupaten Banyumas Tahun 2016

\begin{tabular}{|c|c|c|c|}
\hline No & Variabel & p & Keputusan \\
\hline 1 & 2 & 3 & 4 \\
\hline 1 & $\begin{array}{l}\text { Jenis tempat } \\
\text { penampungan air }\end{array}$ & 0,000 & Ada hubungan \\
\hline 2 & $\begin{array}{l}\text { Penempatan tempat } \\
\text { penampungan air }\end{array}$ & 0,264 & $\begin{array}{l}\text { Tidak } \\
\text { hubungan }\end{array}$ \\
\hline 3 & Sumber air & 0,122 & $\begin{array}{l}\text { Tidak } \\
\text { hubungan }\end{array}$ \\
\hline
\end{tabular}

Tabel 4.17 Lanjutan

\begin{tabular}{clcll}
\hline $\mathbf{1}$ & \multicolumn{1}{c}{$\mathbf{2}$} & $\mathbf{3}$ & \multicolumn{2}{c}{$\mathbf{4}$} \\
\hline $\mathbf{4}$ & $\begin{array}{l}\text { Warna tempat } \\
\text { penampungan air }\end{array}$ & 0,000 & Ada hubungan \\
5 & $\begin{array}{l}\text { Pemakaian abate } \\
0,492\end{array}$ & Tidak & ada
\end{tabular}




\begin{tabular}{rlrlr}
6 & $\begin{array}{l}\text { Pemeliharaan ikan } \\
\text { pemakan jentik }\end{array}$ & 0,817 & $\begin{array}{l}\text { hubungan } \\
\text { Tidak } \\
\text { hubungan } \\
\text { Kebiasaan } \\
\text { membersihkan } \\
\text { tempat }\end{array}$ & 0,027 \\
hubungan & ada \\
8 & $\begin{array}{l}\text { penampungan air } \\
\text { Kebiasaan } \\
\text { membuang barang } \\
\text { bekas }\end{array}$ & 0,340 & $\begin{array}{l}\text { Tidak } \\
\text { hubungan }\end{array}$ & ada \\
9 & $\begin{array}{l}\text { Kebiasaan menutup } \\
\text { tempat } \\
\text { penampungan air }\end{array}$ & 0,194 & Tidak \\
hubungan & ada \\
\hline
\end{tabular}

\section{Hasil Analisis Multivariat}

Tabel 4.18. Analisis Multivariat Regresi Logistik Hubungan Karakteristik Tempat Penampungan Air dan Perilaku Masyarakat dengan Keberadaan jentik Aedes aegypti di Kelurahan Karangklesem Kabupaten Banyumas Tahun 2016

\begin{tabular}{clcl}
\hline No & \multicolumn{1}{c}{ Variabel } & p & OR \\
\hline 1. & Warna TPA & 0,000 & 5,542 \\
2. & Kebiasaan Membersihkan & 0,011 & 5,513 \\
& TPA & & \\
\hline 3. & Jenis TPA & 0,004 & 2,262 \\
\hline
\end{tabular}

\section{Pembahasan \\ Analisis Bivariat Variabel yang Berhubungan Jenis TPA}

Hasil analisis bivariat menggunakan chi-square menunjukkan ada hubungan antara jenis TPA dengan keberadaan jentik Aedes aegypti $(\mathrm{p}=0,000)$. Dan nilai Odd Ratio (OR) 2,262 lebih dari 1 yang berarti secara statistik merupakan faktor risiko keberadaan jentik Aedes aegypti.

TPA berbahan dasar plastik paling banyak ditemukan jentik karena TPA berbahan dasar plastik mempunyai dinding permukaan yang kasar dan luas, selain itu umumnya mempunyai warna dasar yang gelap. TPA berbahan dasar semen yang diperiksa umumnya berlapiskan keramik, walaupun memiliki permukaan yang tidak kasar namun pada umumnya bak memiliki permukaan dinding yang luas sehingga nyamuk senang meletakkan telurnya disana.

Warna TPA

Hasil analisis statistik menunjukan $\mathrm{p}$ value $=$ 0,000 yang menunjukkan adanya hubungan antara warna TPA dengan keberadaan jentik Aedes aegypti. Nilai Odd Ratio (OR) 5,542 yang berarti secara statistik merupakan faktor risiko keberadaan jentik Aedes aegypti. Berdasarkan penelitian yang telah dilakukan oleh Anif Budiyanto (2012) mengenai "Perbedaan Warna Kontainer Berkaitan dengan Keberadaan Jentik Aedes aegypti di Sekolah Dasar" terbukti adanya perbedaan proporsi yang bermakna antara perbedaan warna gelap dan terang dengan keberadaan jentik dengan $\mathrm{p}$ value $=0,02$. Hal ini menyatakan bahwa nyamuk Aedes lebih senang berkembang biak pada TPA yang berwarna gelap.

Kebiasaan membersihkan TPA

Berdasarkan uji statistik menunjukkan p value $=$ 0,027 yang berarti ada hubungan membersihkan TPA dengan keberadaan jentik Aedes aegypti. Nilai Odd Ratio (OR) 5,513 lebih besar dari 1 yang menunjukkan bahwa membersihkan TPA merupakan faktor risiko keberadaan jentik Aedes aegypti.

Hasil observasi di lapangan menunjukkan bahwa responden tidak melakukan kegiatan pengurasan karena TPA memiliki ukuran yang tidak terlalu besar dimana air yang ditampung digunakan untuk keperluan seharihari sehingga air sering diganti setiap hari. Perkembangbiakan telur nyamuk memerlukan waktu 1-2 hari untuk menjadi jentik (Depkes RI, 2005).

Analisis Bivariat Variabel yang Tidak Berhubungan Penempatan TPA

Karakteristik Aedes aegypti sp. pada dasarnya terdapat di dalam rumah, tempat perindukan biasa di bak-bak mandi (air bersih) dan suka hinggap di pakaian yang di gantung di kamar (Adifian dkk, 2013). Namun pada saat ini juga dapat dilihat banyak rumah yang memiliki dua atau tiga lantai. Berkaitan dengan hal itu mungkin perlu ditinjau kembali apakah ada perbedaan antara penempatan TPA didalam rumah yang berada di lantai satu dan lantai dua dengan keberadaan jentik Aedes aegypti.

Sumber Air

Hasil analisis statistik menunjukan $\mathrm{p}=0,122$ yang berarti tidak ada hubungan sumber air dengan keberadaan jentik Aedes aegypti. Jentik Aedes aegypti dalam pertumbuhannya membutuhkan zat-zat organik yang ada dalam air sebagai bahan makanannya serta ditambah dengan suhu yang mendukung yaitu suhu 20$30^{\circ} \mathrm{C}$. Hal ini terpenuhi dari air sumur gali/artesis yang banyak mengandung zat-zat organik yang dihasilkan oleh air tanah.

\section{Pemakaian Abate}

Memutus rantai siklus hidup Aedes aegypti merupakan hal yang diperlukan, namun perlu adanya upaya untuk memberikan informasi yang benar mengenai bubuk abate dan cara penggunaannya. Selain informasi dan pengetahuan yang diberikan pihak puskesmas, adanya pembagian rutin bubuk abate setiap bulannya juga menjadi salah satu solusi untuk menciptakan koordinasi antar masyarakat dengan pihak puskesmas.

Pemeliharaan Ikan Pemakan Jentik

Analisis bivariat menunjukkan p value $=0,817$ yang berarti secara statistik tidak ada hubungan antara pemeliharaan ikan pemakan jentik dengan keberadaan jentik Aedes aegypti. Nilai Odd Ratio (OR) yaitu 0,373 
lebih kecil dari 1 sehingga bukan merupakan faktor risiko keberadaan jentik Aedes aegypti.

Kebiasaan Membuang Barang Bekas

Hasil uji statistik bivariat menunjukkan p value $=$ 0,340 yang artinya tidak ada hubungan kebiasaan membuang barang bekas dengan keberadaan jentik Aedes aegypti. Nilai Odd Ratio (OR) 0,679 lebih kecil dari 1 berarti merupakan bukan faktor risiko keberadaan jentik Aedes aegypti. Hal ini sejalan dengan penelitian yang dilakukan Anggara (2005) di wilayah Kerja Puskesmas Dahlia Kota Makassar yang menunjukkan bahwa tidak ada hubungan antara mengubur barangbarang bekas dengan keberadaan larva Aedes aegypti. Hal serupa juga ditunjukkan oleh Yudhastuti dan Vidiyani (2005) di Surabaya.

Kebiasaan Menutup TPA

Dalam penelitian ditemukan TPA dalam kondisi tertutup namun masih ditemukan jentik. Hal ini dikarenakan desain penelitian adalah cross-sectional sehigga penilaian dilakukan pada saat dilakukan survey. Ketika peneliti sedang melakukan survei, TPA dalam keadaan tertutup namun beberapa waktu sebelumnya dalam keadaan tidak tertutup.

\section{Simpulan dan Saran}

Perhitungan yang telah dilakukan didapatkan hasil House Index (HI) 43,5\%, Container Index (CI) 24\%, Breteau Index (BI) 102\%, dan Angka Bebas Jentik (ABJ) 56,5\%. Hal ini menunjukkan bahwa selain karakteristik TPA yang mendukung adanya tempat perindukan bagi nyamuk Aedes aegypti, perilaku masyarakat juga masih menjadi salah satu faktor yang menyebabkan keberadaan jentik Aedes aegypti di Kelurahan Karangklesem, Kecamatan Purwokerto Selatan.

Berdasarkan hasil penelitian yang dilakukan, terdapat beberapa saran sebagai berikut: Mengetahui dan mengurangi tempat penampungan air (TPA) yang dapat menjadi tempat perindukan nyamuk Aedes aegypti khususnya yang digunakan untuk keperluan sehari-hari seperti bak mandi dan tempayan, serta barang bekas yang ada di sekitar rumah. Meningkatkan koordinasi dengan Puskesmas agar memfokuskan program pemberantasan jentik Aedes aegypti dengan koordinasi antara puskesmas, masyarakat, kader juru pemantau jentik melalui metode pengecekan jentik nyamuk secara rutin dan juga dengan metode $3 \mathrm{M}$ (menguras, mengubur dan menutup). Melakukan penelitian dengan menggunakan studi intervensi agar dapat mengetahui hubungan sebab akibat yang lebih kuat dibandingkan dengan studi cross-sectional.

\section{Ucapan Terima Kasih}

Terima kasih disampaikan kepada warga Kelurahan Karangklesem, Kecamatan Purwokerto Selatan, Kabupaten Banyumas dan Jurusan Kesehatan
Lingkungan Politeknik Kesehatan Kemenkes Semarang sehingga penelitian ini dapat terselesaikan

\section{DAFTAR PUSTAKA}

Aditya Rakhmandanu. 2007. Faktor-faktor Lingkungan yang Berhubungan dengan Keberadaan Jentik Aedes aegypti di Kelurahan Purwokerto Lor Tahun 2007. Purwokerto: Departemen Pendidikan Nasional Universitas Jenderal Soedirman Progran Sarjana Kesehatan Masyarakat Purwokerto.

Ahmad, Watik Pratiknya. 1993. Dasar-dasar Metodologi Penelitian Kedokteran dan Kesehatan. Jakarta: PT Raja Grafindo Persada.

Anggara. 2005. Hubungan $3 M$ dan $3 M$ Plus dengan Keberadaan Larva Aedes aegypti Di Wilayah Kerja Puskesmas Dahlia Kota Makassar Tahun 2005.Skripsi tidak diterbitkan FKM Unhas.

Anif Budiyanto. 2012. Perbedaan Warna Kontainer Berkaitan dengan Keberadaan Jentik Aedes aegypti di Sekolah Dasar. Jurnal Biotek Medisiana Indonesia. Vol. 1.2.2012: 65 - 71.

Aris, Santjaka. 2011.Statistik Untuk Penelitian Kesehatan1. Yogyakarta: Nuha Medika.

Chadijah, Siti., Rosmini., Halimuddin. 2011. Peningkatan Peran Serta Masyarakat dalam Pelaksanaan Pemberantasan Sarang Nyamuk DBD (PSN-DBD) di Dua Kelurahan di Kota Palu, Sulawesi Tengah. Media Litbang Kesehatan Vol. 21 (2).

Departemen Kesehatan RI. Direktorat Jenderal Pengendalian Penyakit dan Penyehatan Lingkungan (DIR.JEN.PP\&PL). 2007a. Survai Entomologi Demam Berdarah Dengue, Jakarta: DIT.JEN. PP \& PL

Djaenudin, Natadisastra dan Ridad agoes. 2009. Parasitologi Kedokteran Ditinjau dari Organ Tubuh Yang Diserang. Jakarta: EGC.

Dinas Kesehatan Provinsi Jawa Tengah. 2006. Profil Kesehatan Provinsi Jawa Tengah Tahun 2006.

Dinas Kesehatan Provinsi Jawa Tengah. Profil Kesehatan Provinsi Jawa Tengah Tahun 2014. Semarang. $\quad$ http://www.dinkesjatengprov.go.id. Diakses tanggal 11 Mei 2015

Direktorat Jenderal dan Penyehatan Lingkungan. 2015. Pencegahan dan Penanggulangan Penyakit Demam 
Dengue dan Demam Berdarah Dengue. Jakarta: Ditjen PPM dan PL.

H.J. Mukono. 2006. Prinsip Dasar Kesehatan Lingkungan Edisi Kedua. Surabaya: Airlangga University Press.

Hadinegoro dan Satari. 2002. Demam Berdarah Dengue. Jakarta: Balai Penerbit FK UI.

Hasyimi dkk. 2009. Tempat-tempat Terkini yang Disenangi Untuk Perkembangbiakan Vektor Demam Berdarah Aedes Sp. Media Litbang Kesehatan Volume XIX Nomor 2 Tahun 2009.

Jaya dkk. 2013. Hubungan Pemberantasan Sarang Nyamuk (PSN) DBD dengan Keberadaan Larva Aedes aegypti Di Wilayah Endemis DBD Kelurahan Kassi-Kassi Kota Makassar. Kesehatan Lingkungan, Fakultas Kesehatan Masyarakat, UNHAS, Makassar.

Kementerian Kesehatan Republik Indonesia. 2010.Buletin Jendela Epidemiologi: Topik Utama Demam Berdarah Dengue (DBD). Jakarta: Pusat Data dan Surveilans Epidemiologi Kementerian Kesehatan RI.

Pusat Data Surveilans dan Epidemiologi. 2010. Buletin Jendela Epidemiologi, Topik Utama Demam Berdarah Dengue (DBD).

Profil Kelurahan Karangklesem Kecamatan Purwokerto Selatan Kabupaten Banyumas Tahun 2015.

Nomitasari dkk. 2012. Perbedaan Praktik PSN 3M Plus Di Kelurahan Percontohan dan Non Percontohan Program Pemantauan Jentik Rutin Kota Semarang. Jurnal Entomologi Indonesia. April 2012, Vol. 9 No. 1, 32 - 37. ISSN: 1829-7722.

Sari dan Darnoto. 2012. Hubungan Breading Place dan Perilaku Masyarakat dengan Keberadaan Jentik Vektor DBD di Desa Gagat Sipat Kecamatan Ngemplak Kabupaten Boyolali. Surakarta. Jurnal Kesehatan, ISSN 1979-7621, Vol. 5, No. 2, Juni 2012: 103 - 109 .

Setyawati Bunga. 2010. Hubungan Karakteristik Kontainer dan Praktek PSN dengan Keberadaan Jentik Aedes aegypti di Kelurahan Genuksari Kota Semarang, Skripsi. Universitas Diponegoro.

Sudibyo Phontas Anton, Moehammadi Noer, Hariyanto Sucipto. 2009. Kepadatan Populasi Larva Aedes aegypti Pada Musim Hujan Di Kelurahan Patemon Surabaya. Skripsi. Universitas irlangga.
Suharsimi, Arikunto. 2010. Prosedur Penelitian Suatu Pendekatan Praktek. Jakarta: Rineka Cipta.

Tri Cahyono. 2014. Pedoman Penulisan Proposal Penelitian dan Karya Tulis Ilmiah/Skripsi (Edisi Revisi Ke Tiga). Purwokerto: Jurusan Kesehatan Lingkungan Purwokerto.

Undang-undang Nomor 32 tahun 2009 tentang Perlindungan dan Pengelolaan Lingkungan Hidup. 